\title{
Evaluating Vancouver's supervised injection facility: data and dollars, symbols and ethics
}

\author{
Don C. Des Jarlais PhD, Kamyar Arasteh PhD, Holly Hagan PhD
}

$\infty$ See related research paper by Bayoumi and Zaric, page 1143

I nsite, Vancouver's supervised injection facility for injection drug users, opened in 2003 under an exemption from Canadian federal drug laws. A substantial amount of research has since been conducted on the facility (www .vch.ca/sis/). Although randomized controlled trials have not been possible, the research has indicated substantial public health benefits associated with the facility's operation.

In this issue, Bayoumi and Zaric present a model of the cost-effectiveness of Insite. ${ }^{1}$ The model's basic comparison is between other interventions for the prevention of HIV infection in Vancouver, such as needle-exchange programs and methadone maintenance treatment, and these interventions plus Insite. Although the authors recognize great potential variation of the cost-effectiveness in their sensitivity analyses, some of their model's assumptions are questionable. Most importantly, the model generates an incidence rate of HIV infection of 5-6 per 100 person-years over their 10-year time horizon. This estimated rate forces us to challenge their costeffectiveness model.

The defining characteristics of successful HIV prevention among injection drug users are the reduction of the HIV incidence rate to a low level, typically less than 2 per 100 personyears at risk, and the maintainance of the reduced rate over long periods..$^{-4}$ In the Vancouver Injection Drug Users Study, the incidence rate of HIV infection among injection drug users in Vancouver was 1-2 per 100 person-years in 2000, before the existence of Insite. ${ }^{5}$ Allowing for a cohort effect in the study, the rate should have remained at $2-3$ per 100 person-years since then.

A comparison with New York City may be helpful here. A large-scale expansion of needle-exchange programs in that city was followed by a reduction in the HIV incidence rate among injection drug users from 4 to 1 per 100 person-years. ${ }^{6}$ If the incidence rate were to return to 4 per 100 person-years, we would conclude that the system for preventing HIV infection among injection drug users in New York City was clearly failing. Similarly, if the rate among injection drug users in Vancouver were now to rise to and remain at 5-6 per 100 person-years, we would have to conclude that something had gone wrong with Vancouver's system to prevent HIV infection.

Successful HIV prevention among injection drug users relies not only on a reduction of the number of unsafe injections, but also on other mechanisms such as partner restriction (in which sharing is confined within small, stable groups) and informed altruism (in which users who know they are sero-

\section{Key points \\ - Insite, Vancouver's supervised injection facility, is currently under threat of being closed. \\ - Estimates of future incidence rates of HIV infection among injection drug users in Vancouver vary greatly, from 2-3 per 100 person-years to 5-6 per 100 person-years. \\ - This variation depends on the assumptions made about the overall effectiveness of efforts to prevent HIV infection in this population. \\ - The number of HIV infections averted per year because of Insite's services also varies with the different assumptions. \\ - Despite these variations, Insite is likely to be cost-effective. \\ - The threat to close Insite appears to be based more on emotional reactions to the facility and drug addicts than to cost-effectiveness analyses.}

positive volunteer to inject last when a syringe is shared). Such mechanisms can greatly reduce HIV transmission without necessarily reducing shared injections. Modelling based on needle sharing that does not include these types of mechanisms is likely to overestimate HIV transmission among injection drug users.

It is inappropriate to assess Insite within a model that assumes HIV prevention among injection drug users is not succeeding in Vancouver as a whole. However, we do not wish to overemphasize our differences, because we still believe that the facility is likely cost-effective. The relation between needle sharing and incident HIV infections is inherently difficult to model. However, the $21 \%$ of injection drug users assumed by Bayoumi and Zaric to be using Insite regularly and to have a decreased frequency of needle sharing clearly have multiple risk factors for HIV infection. We estimate that, in the absence of Insite services, the incidence of HIV infection in this group would be about 4-5 per 100 person-years (about double the rate among injection drug users as a whole). If Insite's services simply reduce this rate to the average of $2-3$

Don Des Jarlais and Kamyar Arasteh are with the Beth Israel Medical Center, Baron Edmond de Rothschild Chemical Dependency Institute, New York, United States. Holly Hagan is with the National Development and Research Institutes, Inc., New York, USA

Editor's note: In Appendix 2 of their article (available at www.cmaj.ca/cgi /content/full/179/11/1143/DC2), Bayoumi and Zaric provide additional information on the design of their cost-effectiveness model and how it was applied in their analysis. 
per 100 person-years among injection drug users in Vancouver, about 20-30 new HIV infections would be averted per year. With allowances for growth in the population of injection drug users over time, this would equal about 250-350 averted infections over 10 years, albeit substantially fewer than the 1191 estimated by Bayoumi and Zaric. Given the estimated lifetime medical cost of $\$ 150000$ to treat HIV, ${ }^{8}$ Insite will be cost saving if it prevents a modest number of HIV infections per year. More importantly, we believe that the threat by the Canadian government in 2007 not to extend Insite's exemption from federal drug laws was not based on assessments of the facility's cost-effectiveness. Instead, it appeared to be based on the symbolic value of Insite as a service that either encourages illicit drug use or provides needed health services to injection drug users.

Recent research has indicated that stigmatization of extreme out-groups such as drug addicts is not simply a matter of a lack of information about the groups but that it involves different mental processes. In their study, Harris and Fiske ${ }^{9}$ found that, although functional magnetic resonance imaging showed activation of the medial frontal cortex while participants were thinking about social groups in general, no such activation was observed when they were thinking about extreme out-groups such as drug addicts. The authors concluded that the participants were showing a reaction of disgust toward drug addicts and were perceiving them to be "less than human."

Decision-making about controversial public health projects such as Insite may thus be primarily a function of emotional reactions to drug addicts of disgust, dehumanization and stigmatization rather than reactions of sympathy, humanity and the right to optimal health for all, which one would hope would be the framework for assessing the effectiveness of public health interventions. Within a disgust/dehumanization framework, effectiveness and cost-effectiveness are usually not important aspects of a program or policy. Rather, it is the congruency between the symbolic value of the program and the emotions of disgust, dehumanization and stigmatization that is critical.

Within a framework designed to protect the health of drug users and of the communities in which they live, it is critical to use the best available evidence to allocate scarce resources. ${ }^{10}$ As noted earlier, almost any intervention that reduces the incidence of HIV infection in a developed country such as Canada is likely to be cost-effective. However, HIV prevention programs for injection drug users should meet 3 other criteria. First, the intervention should be targeted to those at relatively high risk for transmitting HIV. Second, the intervention should be linked to other health and social services. Vulnerable populations such as injection drug users typically have multiple needs; therefore, individual programs should provide multiple services on site and through referrals. Third, the intervention should be supported by drug users and the local community. Such support is needed for the intervention to be used and sustained. Based on the evidence to date, Vancouver's supervised injection facility not only saves costs, it also meets these broader criteria for effectiveness.

Competing interests: None declared.

Contributors: Each of the authors contributed to the content of the article, revised it critically and approved the final version for publication.

\section{REFERENCES}

1. Bayoumi AM, Zaric GS. The cost-effectiveness of Vancouver's supervised injection facility. CMAJ 2008;179:1143-51.

2. Committee on the Prevention of HIV Infection among Injecting Drug Users in High Risk Countries. Preventing HIV infection among injecting drug users in high risk countries: an assessment of the evidence. Washington (DC): Institute of Medicine; 2006.

3. Des Jarlais DC, Hagan H, Friedman S, et al. Maintaining low HIV seroprevalence in populations of injecting drug users. JAMA 1995;274:1226-31.

4. Stimson GV. AIDS and injecting drug use in the United Kingdom, 1987-1993: the policy response and the prevention of the epidemic. Soc Sci Med 1995;41:699-716.

5. Surveillance and Risk Assessment Division. Inventory of HIV incidence and prevalence studies in Canada. Ottawa $(\mathrm{ON})$ : Centre for Infectious Disease Prevention and Control, Infectious Diseases and Emergency Preparedness Branch, Public Health Agency of Canada; 2006.

6. Des Jarlais DC, Perlis T, Arasteh K, et al. HIV incidence among injection drug users in New York City, 1990 to 2002: use of serologic test algorithm to assess expansion of HIV prevention services. Am J Public Health 2005;95:1439-44.

7. Des Jarlais DC, Perlis T, Arasteh K, et al. "Informed altruism" and "partner restriction" in the reduction of HIV infection in injecting drug users entering detoxification treatment in New York City, 1990-2001. J Acquir Immune Defic Syndr 2004; 35:158-66.

8. Kuyper LM, Hogg R, Montaner J, et al. The cost of inaction on HIV transmission among injection drug users and the potential for effective interventions. $J$ Urban Health 2004;81:655-60.

9. Harris LT, Fiske S. Dehumanizing the lowest of the low. Psychol Sci 2006;17:847-53.

10. Des Jarlais DC. Harm reduction - a framework for incorporating science into drug policy [editorial]. Am J Public Health 1995;85:10-2.

Correspondence to: Dr. Don C. Des Jarlais, Beth Israel Medical Centre, Baron Edmond de Rothschild Chemical Dependency Institute, 160 Water St., 24th floor, New York NY 10038, USA; fax 212 256-2570; dcdesjarla@aol.com 